J.B.METZLER 
Georg Toepfer

\section{Historisches Wörterbuch der Biologie}

Geschichte und Theorie der biologischen Grundbegriffe

Band 3:

Parasitismus - Zweckmäßigkeit

Verlag J. B. Metzler

Stuttgart $\cdot$ Weimar 
Bibliografische Information der Deutschen Nationalbibliothek

Die Deutsche Nationalbibliothek verzeichnet diese Publikation in der Deutschen Nationalbibliografie; detaillierte bibliografische Daten sind im Internet über http://dnb.d-nb.de abrufbar.

Gesamtwerk:

978-3-476-02316-2

Band 3:

ISBN 978-3-476-02319-3

ISBN 978-3-476-00461-1 (eBook)

DOI 10.1007/978-3-476-00461-1

Dieses Werk einschließlich aller seiner Teile ist urheberrechtlich geschützt. Jede Verwertung außerhalb der engen Grenzen des Urheberrechtsgesetzes ist ohne Zustimmung des Verlages unzulässig und strafbar. Das gilt insbesondere für Vervielfältigungen, Übersetzungen, Mikroverfilmungen und die Einspeicherung und Verarbeitung in elektronischen Systemen.
(C) 2011 Springer-Verlag GmbH Deutschland Ursprünglich erschienen bei J.B. Metzler'sche Verlagsbuchhandlung und Carl Ernst Poeschel Verlag GmbH in Stuttgart 2011

www.metzlerverlag.de info@metzlerverlag.de 
Inhaltsverzeichnis

Band 1

Einleitung

Artikelverzeichnis

Wortverzeichnis

Abbildungsverzeichnis $\mathrm{Xxv}$

Tabellenverzeichnis $\quad \mathrm{xciii}$

Analogie

Anatomie

Anpassung

Art

Arterhaltung 132

Bakterium 141

Balz 152

Bedürfnis $\quad 156$

Befruchtung 167

Bewusstsein $\quad 172$

Bioethik 205

Biogeografie 231

Biologie 254

Biosphäre 296

Biotop 305

Biozönose $\quad 320$

Brutpflege 344

Diversität $\quad 351$

Einzeller $\quad 366$

Empfindung 373

Entwicklung $\quad 391$

Entwicklungsbiologie 438

Ernährung 442

Ethologie 461

Evolution 481

Evolutionsbiologie $\quad 540$

Feld 553

Form 558

Fortpflanzung $\quad 577$

Fortschritt 606

Fossil

627

Funktion

644

Ganzheit
Band 2

Gefühl 1

Gen 15

Generationswechsel 49

Genetik 54

Genotyp/Phänotyp 59

Geschlecht $\quad 72$

Gewebe 91

Gleichgewicht 98

Hierarchie $\quad 117$

Homologie 131

Individuum 159

Information $\quad 181$

Instinkt 195

Intelligenz 215

Koexistenz 231

Kommunikation 244

Konkurrenz 277

Krankheit 290

Kreislauf 302

Kultur $\quad 340$

Kulturwissenschaft $\quad 374$

Künstliches Leben 399

Lamarckismus $\quad 409$

Leben

420

Lebensform

484

Lebensgeschichte

497

Lernen

507

Mensch

520

Metamorphose

573

Mimikry

592

Modifikation

606

Molekularbiologie

Morphologie

Mutation

Nische

Ökologie

Ökosystem

Organ

Organisation

Organismus
Band 3

Parasitismus 1

Pflanze 11

Phylogenese 34

Physiologie $\quad 88$

Pilz 106

Polymorphismus $\quad 111$

Population 114

Räuber 136

Regeneration 142

Regulation 148

Rekombination $\quad 200$

Rolle, ökologische 203

Schlaf 211

Schutz 221

Selbstbewegung $\quad 231$

Selbstdarstellung $\quad 246$

Selbsterhaltung $\quad 254$

Selbstorganisation $\quad 271$

Selektion $\quad \mathbf{3 0 5}$

Sozialverhalten $\quad 378$

Spiel 402

Stoffwechsel 410

Symbiose $\quad 426$

Systematik 443

Taxonomie 469

Tier 494

Tod 510

Typus $\quad \mathbf{5 3 7}$

Umwelt $\quad 566$

Urzeugung 608

Vererbung $\quad 620$

Verhalten $\quad 653$

Virus $\quad 688$

Vitalismus $\quad 692$

Wachstum 711

Wahrnehmung 717

Wechselseitigkeit $\quad 738$

Zelle $\quad \mathbf{7 6 4}$

Zweckmäßigkeit $\quad 786$

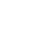

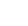

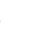

3

1

